\title{
A case of thyroid fibromatosis, a rare lesion of this gland
}

\author{
Joana Simões-Pereira1,2,3, Rafael Adame Cabrera4 and Valeriano Leite ${ }^{1,2,3}$ \\ 'Serviço de Endocrinologia, 2Unidade de Investigação em Patobiologia Molecular (UIPM), Instituto Português \\ de Oncologia de Lisboa, Francisco Gentil, Lisbon, Portugal, ${ }^{3}$ NOVA Medical School/Faculdade de Ciências Médicas,

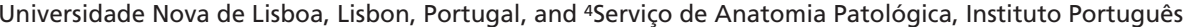 \\ de Oncologia de Lisboa, Francisco Gentil, Lisbon, Portugal
}

Correspondence should be addressed to J Simões-Pereira Email joanasimoespereira@gmail. com

\section{Summary}

Thyroid fibromatosis is a very rare lesion; to our knowledge, there are only four cases reported in the medical literature. Herein, we report the clinical case of a woman with thyroid fibromatosis with a long follow-up (11 years). A 63-yearold female patient, with an increasing multinodular goitre without compressive symptoms, was admitted to total thyroidectomy. The histology revealed a spindle-cell proliferation with fibroblastic characteristics with no atypia and thin capillary vessels. Immunohistochemistry was positive for beta-catenin, focally to desmin and alfa-actin and negative for cytokeratins and CD34. Thyroid cells did not display any features of papillary thyroid cancer. These characteristics were compatible with thyroid fibromatosis. For the past 11 years, the patient has been periodically followed up with neck CTs and she has not shown any signs of recurrence. Thyroid fibromatosis has been associated with invasion of surrounding structures in previous reported cases. However, this aggressive behaviour was not observed in our patient. The most challenging differential diagnosis is with papillary thyroid cancer with fibromatosis-like stroma, in which the malignant component is usually peripheral. Therefore, in these cases, it is mandatory to perform an extensive examination of the resected sample.

\section{Learning points:}

- Fibromatosis is a mesenchymal lesion that consists of an infiltrative proliferation of fibroblasts without atypia.

- Thyroid fibromatosis is a rare entity in this gland. In previously reported cases, it has been associated with an invasive behaviour but this was not the case in our patient.

- When spindle-cell proliferation with fibroblastic/myofibroblastic characteristics is detected on thyroid histology, it is mandatory to exclude a papillary thyroid carcinoma with fibromatosis-like stroma.

\section{Background}

Thyroid fibromatosis is a very rare lesion. To the best of our knowledge, only four cases have been reported in the literature $(1,2,3)$, which makes this diagnosis a poorly defined entity in terms of clinical outcome. Fibromatosis represents a tumour-like lesion originating from the fascia and musculoaponeurotic tissue, frequently with local aggressive behaviour. Only $10 \%$ of these lesions occur in cervical region $(4,5)$, and thyroid involvement is even less frequent. Cervical fibromatosis can present an infiltrative growth pattern putting at risk important structures of the neck, but it does not metastasize (6). Fibromatosis may also evolve with local recurrence (7). Herein, we report the clinical case of a woman with thyroid fibromatosis with 11-years of follow-up. 


\section{Case presentation}

A 63 year-old female patient, with a history of high blood pressure (treated with an angiotensin-convertingenzyme inhibitor), presented, in 2004, in another institution, with a recent onset of an increasing cervical mass without compressive symptoms. A multinodular goitre was detected and she was submitted to fine-needle aspiration cytology (FNAC) of one of the nodules, which revealed a colloid goitre. Detailed descriptions of thyroid ultrasound and thyroid function tests taken at that time were not available.

\section{Investigation}

A multinodular goitre was detected and she was submitted to FNAC of one of the nodules, which revealed a colloid goitre. Detailed descriptions of thyroid ultrasound and thyroid function tests taken at that time were not available.

\section{Treatment}

She was then submitted to total thyroidectomy.

\section{Outcome and follow-up}

The resected piece revealed a nodule measuring $55 \times 40 \times 30 \mathrm{~mm}$ with fibrous consistency and fascicular aspect; the remaining parenchyma evidenced a nodular

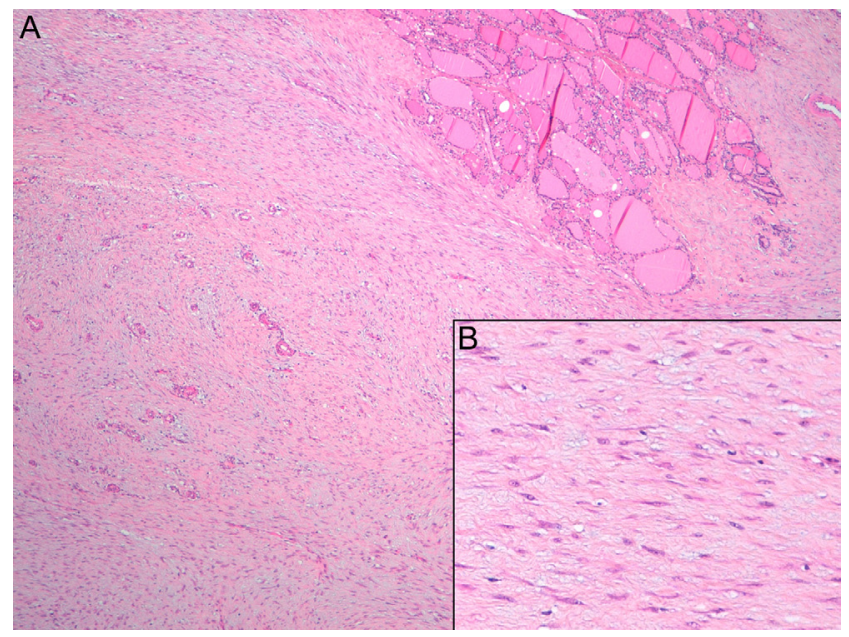

Figure 1

(A) Bland spindle-cell proliferation arranged in ill-defined fascicles, infiltrating into the thyroid follicles. (B) The cells lack cytological atypia and have small pale staining nuclei. surface with colloid brightness. On microscopic examination a spindle-cell proliferation with fibroblastic/myofibroblastic characteristics with no atypia, thin capillary vessels and perivascular oedema were observed (Fig. 1). Immunohistochemistry was positive for beta-catenin, focally for desmin and negative for cytokeratins, CD34 and alfa-actin (Fig. 2). So, the resected nodule corresponded to the fibromatosis component surrounded by colloid goitre. Papillary thyroid cancer was not found after extensive sampling. These features were compatible with thyroid fibromatosis.

After thyroidectomy, she developed dysphonia and dyspnoea due to paralysis of both vocal chords. $\mathrm{CO}_{2}$ laser posterior cordotomy of the left vocal chord was performed post-operatively, dyspnoea worsened and the patient was submitted to urgent tracheostomy. In the following 5 years, several surgeries were attempted to decannulate her but were unsuccessful. The first two surgical approaches consisted of $\mathrm{CO}_{2}$ laser posterior cordotomy of the left vocal chord and the third surgery of $\mathrm{CO}_{2}$ laser posterior cordotomy on the right side. Her last surgery, 4 years after the thyroidectomy, consisted of a laryngoplasty. Unfortunately, her glottic lumen was not sufficient to allow decannulation. In all of these surgeries, peri-tracheostomal granulation tissue was surgically removed. Histological examination of biopsies taken at those surgeries did not reveal any loco-regional invasion or recurrence of the original lesion. For the past 11 years, the patient has been

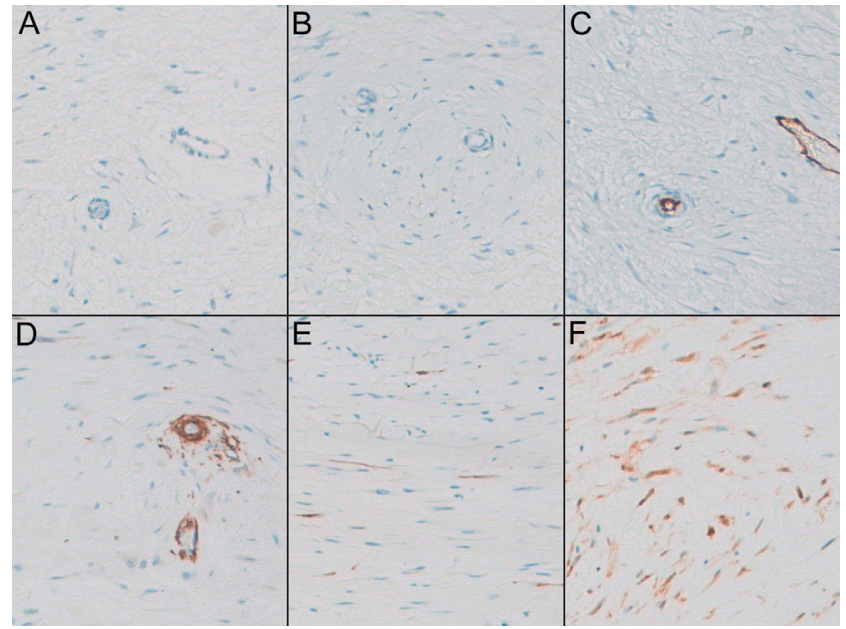

Figure 2

Immunohistochemistry showed negativity for cytokeratins AE1/AE3 (A) and CAM5.2 (B), CD34 (C) and smooth-muscle actin (D). There was very weak and focal staining for desmin (E) and nuclear positivity for $\beta$-catenin (F). 
periodically followed up with neck CTs and she has not shown any signs of recurrence. TSH has been within the normal range, under supplementation with levothyroxine, and serum thyroglobulin levels have remained stable between 0.3 and $2.0 \mathrm{ng} / \mathrm{mL}$ (with negative anti-thyroglobulin antibodies).

\section{Discussion}

Fibromatosis is a mesenchymal lesion that consists of an infiltrative proliferation of fibroblasts without atypia. Neck fibromatosis is usually associated with invasion of surrounding structures. In fact, three of the four previously described cases of thyroid fibromatosis, evidenced invasion of the surrounding structures (muscles, vessels, etc.) $(1,2,3)$, but complications deriving from the thyroidectomy were not clearly described in those cases. This infiltrative behaviour was not observed in our patient - we admit that this non-invasive behaviour was related to the fact that the fibromatosis component corresponded to a welldefined nodule, measuring $55 \mathrm{~mm}$, restricted to the thyroid. We believe that her vocal chords paralysis was caused by injury of laryngeal nerves during surgery, given that she only complained of dysphonia and dyspnoea after thyroidectomy. Another interesting fact of this clinical entity is its pathogenesis - one of the patients reported by Schwarlmüller et al. (3) evidenced a previous history of neck injury with a wire and, therefore, the fibromatosis was considered to be a fibrous proliferative reaction to a foreign body.
A short description of the four reported cases is displayed in Table 1.

The differential diagnosis of a progressively enlarging and firm thyroid gland usually includes uncommon conditions like anaplastic or poorly differentiated thyroid carcinoma, primary thyroid lymphoma or Riedel thyroiditis. Thyroid fibromatosis is an even more rare cause of thyroid growth. When spindlecell proliferation with fibroblastic/myofibroblastic characteristics is detected on thyroid histology, it is mandatory to exclude a papillary thyroid carcinoma with fibromatosis-like stroma (PTC-FLS), which represents only a tiny fraction (up to $0.5 \%$ ) of all PTCs (8). The stromal reaction usually represents $60-80 \%$ of the tumour volume, exhibiting characteristics of both fibroblasts and smooth-muscle cells, suggesting that it is derived from myofibroblasts. The pathogenesis of the stromal component is still a matter of debate: some authors believe that it can represent a reactive proliferation to some form of injury (as in the case reported by Schwarzlmüller et al. (3)), while others advocate an autonomous proliferation of stromal cells (9). It may be difficult to obtain a correct diagnosis of PTC-FLS by FNAC, given that most of it is composed by a bulky stroma, making the aspiration of the malignant component hard to obtain. Moreover, as previously shown (10), the malignant epithelial component, containing cells with clear and grooved nuclei, is usually located at the periphery of the tumour, which may be missed by the pathologist. Therefore, when thyroid fibromatosis is diagnosed, PTC-FLS should be carefully

Table 1 Summary of the cases previously reported in the literature.

\begin{tabular}{|c|c|c|c|c|c|c|}
\hline Authors & Relevant history data & $\begin{array}{c}\text { Age at } \\
\text { diagnosis }\end{array}$ & Gender & Surgery & $\begin{array}{l}\text { Invasiveness/ } \\
\text { adherence }\end{array}$ & $\begin{array}{l}\text { Evolution after } \\
\text { surgery }\end{array}$ \\
\hline Present case report & $\begin{array}{l}\text { Increasing cervical } \\
\text { mass without } \\
\text { compressive } \\
\text { symptoms }\end{array}$ & 63 & $\mathrm{~F}$ & Total thyroidectomy & No & NED \\
\hline Sinha et al. (1) & $\begin{array}{l}\text { Increasing swelling of } \\
\text { thyroid and } \\
\text { dysphonia }\end{array}$ & 26 & $\mathrm{~F}$ & $\begin{array}{l}\text { Debulking of the } \\
\text { thyroid mass in } \\
\text { front of trachea }\end{array}$ & $\begin{array}{l}\text { Major vessels of } \\
\text { neck and } \\
\text { trachea }\end{array}$ & Not mentioned \\
\hline Samsi et al. (2) & $\begin{array}{l}\text { Increasing swelling of } \\
\text { thyroid }\end{array}$ & 60 & $\mathrm{~F}$ & $\begin{array}{l}\text { Near total } \\
\text { thyroidectomy }\end{array}$ & $\begin{array}{l}\text { Surrounding } \\
\text { muscles }\end{array}$ & NED \\
\hline Schwarzlmfüller et al. (3) & $\begin{array}{l}\text { Past history of neck } \\
\text { injury with a wire }\end{array}$ & 34 & $\mathrm{~F}$ & $\begin{array}{l}\text { Resection-extension } \\
\text { not clearly } \\
\text { mentioned }\end{array}$ & $\begin{array}{l}\text { Muscles, fat } \\
\text { tissue, lymph } \\
\text { nodes, salivary } \\
\text { gland }\end{array}$ & $\begin{array}{l}\text { Recurrence } \\
4 \text { years after } \\
\text { first surgery }\end{array}$ \\
\hline Schwarzlmfüller et al. (3) & Multinodular goitre & 68 & $\mathrm{~F}$ & $\begin{array}{l}\text { Resection-extension } \\
\text { not clearly } \\
\text { mentioned }\end{array}$ & No & NED \\
\hline
\end{tabular}

F, female; NED, no evidence of disease. 
excluded. Given the rarity of thyroid fibromatosis, there are no formal recommendations in the literature to follow these patients. In one of the four published cases of thyroid fibromatosis, the patient evidenced a local recurrence 4 years after thyroidectomy (3) so we decided to follow this patient annually, not only to exclude any local recurrence, but also to determine serum thyroglobulin levels considering the difficult differential diagnosis with PTC-FLS.

Our clinical report describes the case of a patient with thyroid fibromatosis with the longest (11 years) follow-up reported to date and, so far, no signs of recurrence have become apparent.

\section{Declaration of interest}

The authors declare that there is no conflict of interest that could be perceived as prejudicing the impartiality of the research reported.

\section{Funding}

This research did not receive any specific grant from any funding agency in the public, commercial or not-for-profit sector.

\section{Patient consent}

We confirm that written informed consent was obtained from the patient for publication of the submitted article and accompanying images.

\section{Author contribution statement}

J S-P and V L were the physicians responsible for the patient. R A C confirmed the diagnosis and provided the photographs.

\section{References}

1 Sinha AN, Rao AS, Sinha A \& Arora R 1998 Fibromatosis of thyroid gland-a case report. Indian Journal of Otolaryngology and Head and Neck Surgery 50 385-386. (doi:10.1007/BF03000695)

2 Samsi AB, Shah HK, Vaidya A, Pai PR, Deshmane U \& Sane SY 1992 Fibromatosis of thyroid gland (a case report). Journal of Postgraduate Medicine 38 36-37.

3 Schwarzlmüller B \& Hofstädter F 1978 Fibromatosis of the thyroid gland region. An electron-microscopic and enzyme-histochemical study. Virchows Archiv. A, Pathological Anatomy and Histology $\mathbf{3 7 7}$ 145-155.

4 Seper L, Bürger H, Vormoor J, Joos U \& Kleinheinz J 2005 Aggressive fibromatosis involving the mandible - case report and review of the literature. Oral Surgery, Oral Medicine, Oral Pathology, Oral Radiology Erratum in: Oral Surgery, Oral Medicine, Oral Pathology, Oral Radiology 99254.

5 Rodriguez-Bigas MA, Mahoney MC, Karakousis CP \& Petrelli NJ 1994 Desmoid tumors in patients with familial adenomatous polyposis. Cancer 74 1270-1274. (doi:10.1002/ 1097-0142(19940815)74:4<1270::AID-CNCR2820740415> 3.0.CO;2-7)

6 Abdelkader M, Riad M \& Williams A 2001 Aggressive fibromatosis of the head and neck (desmoid tumours). Journal of Laryngology and Otology 115 772-776. (doi:10.1258/0022215011909116)

7 Masson JK \& Soule EH 1966 Desmoid tumors of the head and neck. American Journal of Surgery 112 615-622. (doi:10.1016/00029610(66)90331-X)

8 Chan JK, Carcangiu ML \& Rosai J 1991 Papillary carcinoma of thyroid with exuberant nodular fasciitis-like stroma. Report of three cases. American Journal of Clinical Pathology 95 309-314. (doi:10.1093/ ajcp/95.3.309)

9 Wu Z, Chu X, Fan S, Meng X \& Xu C 2013 Papillary thyroid carcinoma with fibromatosis-like stroma: a case report and review of the literature. Oncology Letters 5 215-217. (doi:10.3892/ ol.2012.993)

10 Inaba M, Umemura S, Satoh H, Ichikawa Y, Abe Y, Kirokawa K, Sakai H \& Osamura RY 2002 Papillary thyroid carcinoma with fibromatosis-like stroma: a report of two cases. Endocrine Pathology 13 219-225. (doi:10.1385/EP:13:3:219)

Received in final form 9 August 2016

Accepted 16 September 2016 